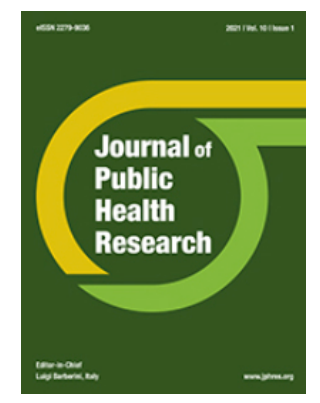

Journal of Public Health Research

elSSN 2279-9036

https://www.jphres.org/

Publisher's Disclaimer. E-publishing ahead of print is increasingly important for the rapid dissemination of science. The Journal of Public Health Research is, therefore, E-publishing PDF files of an early version of manuscripts that undergone a regular peer review and have been accepted for publication, but have not been through the copyediting, typesetting, pagination and proofreading processes, which may lead to differences between this version and the final one.

The final version of the manuscript will then appear on a regular issue of the journal. E-publishing of this PDF file has been approved by the authors.

J Public Health Res 2021 [Online ahead of print]

To cite this Article:

Binte Aamir F, Ahmad Zaidi SM, Abbas S, et al. Non-compliance to social distancing during COVID-19 pandemic: A comparative cross-sectional study between the developed and developing countries. J Public Health Res doi: 10.4081/jphr.2021.2614 


\title{
Non-compliance to social distancing during COVID-19 pandemic: A comparative cross- sectional study between the developed and developing countries
}

\section{Faiqa Binte Aamir ${ }^{1}$, Syeda Maria Ahmad Zaidi', Saadia Abbas ${ }^{1}$, Syed Roohan Aamir ${ }^{1}$, Syed Nauman Ahmad Zaidi ${ }^{2}$, Karishma Kanhya Lal ${ }^{1}$, Syeda Sadia Fatima ${ }^{3 *}$}

\author{
${ }^{1}$ Medical College, Aga Khan University, Karachi, Sindh, Pakistan \\ ${ }^{2}$ Medical College, United Medical College, Karachi, Sindh, Pakistan \\ ${ }^{3}$ Biological and Biomedical Sciences, Aga Khan University, Karachi, Sindh, Pakistan
}

Correspondence: Dr. Syeda Sadia Fatima (M.B.B.S., M.Phil, PhD, FHEA (UK)), Assistant Professor, Department of Biological and Biomedical Sciences, Aga Khan University, Stadium Road, Karachi-74800, Pakistan. Phone:+922134864564 Email: sadia.fatima@aku.edu

Acknowledgements: Society for Promoting Innovation in Medical Education (SPIE), The Aga Khan University; Minahil Fatima, Abdul Wassay Shaikh, Halima Usman, Ubaidah Sohail Salat, Muhammad Bin Mobin, Safa Farhan.

Author contribution: FBA - conceptualisation, data collection, data analysis, manuscript writing, editing SMAZ - conceptualisation, data collection, manuscript writing, editing SA conceptualisation, data collection, manuscript writing, editing SRA - data collection, manuscript writing SNAZ- data collection, manuscript writing KKL - conceptualisation, data collection, data analysis, reviewing, mentoring SSF - conceptualisation, data collection, data analysis, reviewing, mentoring. All authors have contributed significantly, and all authors agree with the content of the manuscript. 
Conflict of interest: The authors declare that they have no conflict of interest.

Availability of data and materials: All data generated or analysed during this study are included in this published article and in supplementary information files.

Ethics approval and consent to participate: The study was approved by the Ethics and Review Committee at The Aga Khan University (ERC approval number -2020-5242-14639). An informed consent was obtained from all study participants and all methods were carried out in accordance with relevant guidelines and regulations.

Patient consent for publication: Not applicable.

Informed Consent: The manuscript does not contain any individual person's data in any form.

\title{
Significance for public health
}

Through this research design, we hope to identify the socioeconomic and demographic factors, and their impact on people's behaviours and attitudes towards adopting social distancing protocols to protect themselves and those around them from the SARS-CoV-2 virus. By understanding the population's mindset and the factors that contribute to governing their behaviours, government policy makers can then employ short- and long-term strategies to address these components, and pass laws that have a higher probability of being accepted and followed by the masses. This study will further assess socioeconomic and cultural reasons that result in variations to compliance by comparing the difference in behaviours and attitudes adopted towards social distancing in both the developed and the developing countries.

\begin{abstract}
Background: Despite mass vaccination campaigns, the world has seen a steady rise in the number of SARS-CoV-2 cases, with 178,765,626 cases and 3,869,994 COVID-19 related deaths by June $19^{\text {th }}, 2021$. Therefore, it is important to enforce social distancing to control its spread.
\end{abstract}


With the variation observed in the severity of the pandemic in different countries, it is also imperative to study the social distancing behaviors amongst the population in the developed and the developing countries.

Methods: In this cross-sectional study, a total of 384 participants from 14 different countries were surveyed via an online REDCap form.

Results: In this study it was highlighted that despite adequate knowledge, the overall compliance to COVID-19 related preventive measures remains poor, the lowest being in the senior age group ( $\geq 65$ years), and the highest being in adults aged between $25-64$ years. ( $p$ value $=0.003$ ) Population from the developing countries were more compliant to all preventative measures against COVID-19 spread, except for handwashing, where the difference between the two populations remained insignificant. ( $\mathrm{p}$ value $=0.038,<0.001,0.016$ ) Socioeconomic status, prior history of COVID-19 infection or presence of comorbidities did not significantly affect compliance rates, however, participants with no prior history of this infection were found to be more compliant to donning a mask in public as compared to those with a positive history. (p value $=0.044)$

Conclusion: Since compliance remains subpar in both the developing and the developed countries, mass campaigns about COVID-19 related preventive measures remain essential in controlling the disease spread.

Keywords: Non-compliance, COVID-19, Social distancing, socio-economic

\section{Introduction}

Coronavirus Disease 2019 (COVID-19) is a highly contagious illness, caused by SARS-CoV-2, a virus that was first identified to have caused disease in areas of Wuhan, China. ${ }^{1}$ As of March $11^{\text {th }}$, 2020, the World Health Organization declared Coronavirus Disease 2019 (COVID-19) caused by SARS-CoV-2 virus to be a global emergency and a pandemic. The first reported COVID-19 case in Pakistan was on $27^{\text {th }}$ February $2020 .^{2}$ Nearly more than a year later, by April $15^{\text {th }}, 2021$, the figure had risen to an appalling 739,818 cases with 15,872 mortalities. The situation in other 
countries is even worse. For example, in the UK alone, more than 4.3 million tested positive by April 15th, and there were 127,161 fatalities. Globally, as of April 15 ${ }^{\text {th }}, 138,923,779$ cases have been reported and there are 2,987,871 confirmed deaths. ${ }^{3}$ Unfortunately, these numbers may be under reported since diagnostic resources remain a precious commodity. ${ }^{1}$

COVID-19 may present with a latent period where infected individuals may remain asymptomatic, thus increasing the possibility of spread of the disease. Therefore, it is advisable to avoid crowds and to observe social distancing which primarily involves closure of public places, such as malls and bazaars; and discourages from social gathering in general. ${ }^{4}$ Isolation is imperative for those who have been diagnosed with COVID-19; and caretakers and healthcare providers should wear adequate personal protective equipment. At community level, proper hand washing techniques should be followed, and infected surfaces should be cleaned with hypochlorite or hydrogen peroxide. ${ }^{1}$ Despite the advent of vaccinations and vaccination programs across the globe, COVID19 cases are on a steady rise. The Centre for Disease Control and Prevention urges vaccinated individuals to exercise caution as well by avoiding medium to large scale gathering, and poorly ventilated areas. ${ }^{5}$ These preventative measures are to be followed strictly to limit spread and break the chain of transmission of the disease.

Since social distancing remains such an important component of prevention and control of COVID-19, it is imperative to assess the various factors that affect its utility. Demographic features, lack of education, disparity in socioeconomic statuses, overpopulation, strict religious views, and misconceptions can contribute to varying response to social distancing. Additionally, despite free availability of vaccines, by May $25^{\text {th }}, 2021$, only $0.6 \%$ of the population had been fully vaccinated. ${ }^{6}$ If factors are explored, it will help officials to counter these obstacles and improve people's response, thereby containing spread of the disease. The study will also assess the changes in perception to social distancing, as well as perspectives on caretaking, if a close family member is affected. By doing so, it will help draw comparisons between the attitude and practices observed by affected and unaffected families during the pandemic. Additionally, the study aims to explore the attitude and practices towards social distancing in both first and third world countries. By comparing the two populations, socioeconomic and cultural reasons that result in variations to compliance will be assessed 


\section{Methods}

\section{Study Design}

This cross-sectional study was based on an online survey which was conducted on the general population in Karachi, Pakistan and in other developing and developed countries listed according to the Department of Economic and Social Affairs of the United Nations Secretariat between December 2020 till March 2021. ${ }^{7}$ Study sample was taken from 14 different countries out of which 7 were developing (Pakistan, India, UAE, Sudan, Turkey, Malaysia, Egypt) and 7 were developed countries (USA, Canada, Australia, UK, Germany, Ireland, Netherland). The survey tool designed by the research team consisted of closed-ended questions assessing knowledge, attitude, and practices towards the COVID-19 pandemic as well as basic sociodemographic characteristics of the study population. This survey tool underwent face validity by experts at the Biological and Biomedical sciences department at The Aga Khan University Hospital (AKUH) and was manipulated until final approval was obtained, following which the survey was sent to The Ethics and Review Committee at The Aga Khan University for approval. (ERC approval number -20205242-14639) Upon receiving the ERC approval, the survey was distributed using REDCap (Research Electronic Data Capture) a secure, web-based software platform designed to support data capture for research studies. ${ }^{8}$

\section{Study Setting and Duration}

To obtain a sizable sample from both the developed and the developing countries and to allow for fair comparison between the two, this REDCap survey was circulated amongst the general population globally via different social media platforms without any direct contact with the participants. The questionnaire was also shared on various survey exchange groups targeting mainly students who represent a key demographic of countries across the world. Our database was further expanded by recruiting students to conduct data collection in collaboration with the Society of Promoting Innovation in Medical Education (SPIE), a student-run research-oriented organization, AKUH. The first ten students to sign up for data collection were recruited and if any student was unable to complete the data collection, the next person on the list was approached. 
These data collectors were instructed to obtain ten responses each from two developed countries and two developing countries, so that each person was assigned to obtain forty samples in total. Each recruited individual was also provided with a list highlighting both the developed and the developing countries as prepared by the Department of Economic and Social Affairs of the United Nations Secretariat. (7) On managing to achieve the target of getting 40 people to fill the form, the data collectors were awarded with an AKUH endorsed certificate of acknowledgement. This process of data collection was carried out over a period of 4 months, from $1^{\text {st }}$ December 2020 to $30^{\text {th }}$ March 2021. During this period of data collection, Pakistan saw a peak in COVID-19 cases during the second wave, with the third wave beginning in mid-March. ${ }^{9}$ Data was collected until $15 \%$ over the required sample size was achieved. This was done to account for forms being filled incompletely or being filled by people who fell under the exclusion criteria.

\section{Study Participants and Sampling}

Subjects below the age of 18 were excluded from the study. Since the questionnaire was distributed in English, people who could not read and understand the language were also not included. Convenience sampling was used to recruit participants to obtain the desired sample size of 384 participants as calculated using a 95\% confidence interval via openepi.com. Digital informed consent was procured from all participants prior to filling the questionnaire. A De-Identification code (D-ID) was assigned by REDCap to each participant to maintain confidentiality and ensure privacy of data. All the information was kept in a secure sheet accessible to only the research team.

\section{Variables}

Independent variables in the study included sociodemographic factors including gender, age, income, education, country of residence, and living conditions. Information regarding self and family comorbidities as well as positivity for the COVID-19 infection was also considered as independent data. Participant responses regarding the practices they were adopting to protect themselves from contracting the disease were used as reference to define compliance to infection safety protocols, which in turn was analysed as dependent data. Compliance, hence, was defined as adherence to practices including washing hands, wearing masks in public places, maintaining a safe distance from people to minimize human contact, and limiting physical human interaction by 
decreasing the frequency of going out, and only leaving the house during emergencies or when deemed absolutely necessary.

\section{Statistical Analysis}

Statistical analysis was done using Statistical Package for the Social Sciences version 25.0. The outliers, which consisted of data showing the number of rooms in the house and number of family members to be greater than 20, were removed prior to the analysis. For continuous quantitative data, descriptive statistics such as frequency, mean and median were used whereas for categorical qualitative data chi square and independent $\mathrm{T}$ test were used. For nonparametric data Kruskal Wallis test was performed to measure the association between variables. A p value of $\leq 0.05$ was considered as significant in all the tests.

\section{Results}

Out of the 432 responses filled on REDCap, 38 responses which were either incomplete or had outlier data set were removed before the analysis. The demographic of the participants is described in Table 1. The mean age of the respondents was 29.4 years and out of the 394 respondents, $58.9 \%$ were males. Around $3 / 5^{\text {th }}$ of the population belonged to developing countries, out of which half of the responses were collected from Pakistan. $60.7 \%$ of the population earned less than Rs.200,000 or USD 4500 per month and the highest number of respondents had completed a bachelor's degree. Majority of the respondents and their family members did not have a history of contracting COVID-19 disease and neither had any comorbidities.

In the study it was found that adults aged 25 to 64 years were overall more compliant than other age groups especially when it came to keeping a safe distance from people where the difference is statistically significant $(\mathrm{p}$ value $=0.003)($ Table 2$)$. Respondents from developing countries were significantly more adherent to the preventative measures against COVID-19 except for in hand washing compliance where the difference remained insignificant ( $\mathrm{p}$ values $=0.038,<0.001,0.016$ ) (Table 2). In both the developing and developed countries respondents with monthly salary less 
than Rs. 200,000 or USD 4500 were found to be marginally more compliant than the rest however, the difference remains insignificant (Table 2). Education status, presence of history of prior SARSCoV-2 infection or comorbidities, presence of family members with comorbidities and COVID19 infection did not affect the compliance rates to the preventative measures against COVID-19 in both developing and developed countries however, participants who did not have a prior history of SARS-CoV-2 infection in the developing countries had a significantly higher compliance to wearing mask when going outside as compared to those who had a positive self-COVID-19 history $(\mathrm{p}$ value $=0.044)$ (Additional file 1). Additionally, participants with no family history for comorbidities in the developing countries were more compliant to hand washing and to donning a mask as compared to those who had a positive family history for comorbidities ( $p$ value $=0.035$ ) (Additional file 1).

There was no significant difference in overall compliance when compared to educational and economic status of the respondents (Table 2). The presence of positive COVID-19 history of the respondents and their family members did not bring about changes in their behaviour towards the pandemic however, individuals who contracted COVID-19 prior to the study had significantly reduced their unnecessary visits outside their homes. The presence of comorbidities among the individuals did not significantly impact their behaviour towards the pandemic however, respondents with family members suffering from comorbidities had a significantly higher compliance to proper hand washing etiquettes as compared to those who did not have any family member with significant risk factors for the disease (Table 2)

Overall, most of the respondents were well educated about the COVID-19 symptoms, its mode of transmission and the preventative measures against it however, higher number of respondents from developed countries were well-aware about the virus as compared those from developing countries (Figure 1A). 76.1\% of the respondents from the developed nations and 57.3\% of respondents from developing countries were well-aware about keeping a safe distance of 6 feet in public, $95.5 \%$ from developed and $92.5 \%$ from developing countries knew about the symptoms of a COVID-19 infection, 98.1\% of subjects from developed and 95\% from developing countries knew about preventative measures that should be taken against SARS-CoV-2 infection and 92.3\% developed countries responses and $85.8 \%$ of developing countries reflected adequate literacy about mechanism of COVID-19 spread among population (Figure 1A). 


\section{Discussion}

In this study participants from 14 different countries, both developing and developed, were targeted to assess adherence to social distancing measures during the COVID-19 pandemic. Factors such as demographic features, gaps in knowledge, essential behaviours, and practices regarding the pandemic, as well as association with self and family COVID-19 positivity were accounted for, to assess difference in compliance in the developed and developing world.

Majority of the participants in this study are from Pakistan and the USA (from the developing and developed category respectively). In Pakistan, the first case was identified on February 26th, 2020, whereas COVID-19 was introduced in the USA nearly a month prior, with the first case emerging on January 20th. In fact, most developed countries including Canada, Germany and the UK had isolated positive cases by the end of January 2020. ${ }^{10}$ Unlike most of Europe and the USA, developing countries like Pakistan had the added time required to formulate, implement, and execute the necessary policies. Perhaps for this reason, a greater number of participants from the developing world were found to be more compliant in this study; and there is a significant difference between the developed and developing countries in maintaining safe distance and decreasing the frequency of going out, as well as in the usage of face masks. Timely media campaigns and imposition of strict measures may have contributed to increased compliance in the developing world. Furthermore, it was imperative for developing countries to invest in preventative measures as the health system is poorly designed to be able to keep up with the onslaught of positive cases. These countries lack the ability to scale up testing and treatment in times of crisis. For this very reason, India's health system, for example, has been overwhelmed during the second wave and India's testing rate remains poor. In contrast to the UK testing 0.5 million individuals daily, India had run a total of only 1.75 million PCR samples by $27^{\text {th }}$ April $2021 .{ }^{11}$ Large scale outbreaks acutely overburden health services, even more so when health-care expenditure is largely out of pocket, and tertiary hospitals are scarce and rarely internationally accredited, such as is the case in most developing countries. ${ }^{12}$ Healthcare provision may be easily and severely overwhelmed in developing countries, therefore prompting administrations to endorse and encourage compliance to preventative measures. Conversely, countries such as the USA ensure that citizens are insured and a healthcare delivery system is in place, which may be attributed to decreased importance given to preventative measures in these countries. With the 
advent of vaccination programs, organizations such as the Centres for Disease Control and Prevention (CDC) have allowed individuals to resume social activities without the usage of masks or physical distancing, unless otherwise stated by the relevant authorities. ${ }^{13}$ Consequently, 20 states including Florida have lifted their mandate on compulsory usage of masks in public. ${ }^{14}$ The Cleveland Clinic and the WHO argue that despite being vaccinated, individuals can still be asymptomatic carriers of the disease and may put susceptible individuals at risk. ${ }^{15}$ Noncompliance for this reason may have detrimental effects on health as vaccines are not $100 \%$ efficacious, and individuals with comorbidities remain at a higher risk for serious complications. ${ }^{16}$

In the current study, there is significant variation within the developing countries subgroup that had previously tested positive for COVID-19 for compliance to wearing masks in public, with most subjects opting to forgo the use of this personal protective equipment ( $\mathrm{p}$ value $=0.044$ ). There is also a significant difference in avoidance to going out in the group that was involved with care of COVID positive family members ( $\mathrm{p}$ value $=0.018$ ), with 58 participants choosing to not comply to the safety measure versus 37 who maintained quarantine. Though not significant, trends from developed countries were the same; and participants chose not to comply with preventive measures. This could be attributed to the view that once infected, antibodies are generated against the virus granting them long term immunity. According to the $\mathrm{WHO}$, antibody titres in infected individuals can vary depending on the severity of symptoms they experience, with asymptomatic individuals having the lowest titres levels. There is insubstantial data on the level of antibodies required to confer immunity and the duration for which they last post infection. ${ }^{17}$ Furthermore, this study showed significant association to compliance to hand washing and mask usage within family members with comorbidities from the developing countries. ( $\mathrm{p}$ value $=0.035$ ) Those with no family history for comorbidities were found to be more compliant. Sanyaolu et al. have reported increased hospitalization, ICU admissions and high mortality in people with comorbidities such as diabetes, hypertension, chronic lung disease and cardiovascular disease; and have called for mass campaigns to increase awareness amongst these individuals. ${ }^{18}$

Majority of the males, in this study, were found to be more compliant to preventative measures, which include proper hand washing techniques, use of face masks in public, social distancing as well as decreasing the overall frequency of going out unnecessarily. In comparison women were found to be less compliant which, especially in developing countries such as India and Pakistan, could be attributed to the clear-cut gender roles. Men are expected to be the bread earners and thus 
expected to go out; and therefore, obligated to follow the rules and regulations laid down by their employers. During the pandemic, the aforementioned measures are mandatory to follow in the workplace. Workplaces prioritized working remotely and carrying out frequent screening for employees to minimize transmission. ${ }^{19}$ Conversely, women may be undereducated and excluded from social discussions which limits their knowledge on health conditions and had to adequately manage them. Women in both developed and developing countries are more involved in reproductive, unpaid labour than men. ${ }^{20}$ Additionally, men are more likely to seek health related advise from licensed practitioner in a formal healthcare setting, whereas women lean more towards traditional healing methods. Even so, in this study, the frequency of male participants was greater (58.9\% males compared to $41.1 \%$ females) which could account for the disparity in results. However, similar findings have been reported in a previous study by Zhong et al., wherein females had markedly decreased compliance to safety measures during the pandemic. ${ }^{21}$

In this study, there is a significant difference within the age groups in compliance to safe distancing in which adults have the highest rate of compliance in both the developing and the developed countries. The senior age group had the lowest rate of compliance (1.77\%). Senior citizens are largely reliant on other members of the family and may not be up to date on current affairs, thus decreasing their compliance. If seniors are living in isolation or residing in old homes, their interaction with well-informed individuals may be limited, adding to the noncompliance. In these participants, comorbidities and chronic illnesses decrease compliance rate to less than $50 \%{ }^{22}$ Additionally, in Pakistan, $64 \%$ of the population is less than 30 years of age, with $29 \%$ of these falling between 15-29 years. ${ }^{23}$ This generation gap implies that the older generation may not be as proficient with technology and have reduced access to social media, which if used correctly can be an excellent source of information. Even though adolescents are well versed with online platforms, they may be unable to filter the useful information and are generally found to be engaged in high-risk behaviours and have a 50-70\% noncompliance rate to management and treatment. ${ }^{22,24}$ Adults in this study were most compliant to pre-emptive measures $(41.2 \%$ adults maintained social distancing). Individuals in the adult age groups not only have increased access to information but are also able to better process it. Additionally, they are responsible for the household and form the major workforce; and are obliged to maintain safe practices.

In contrast to the variations in practice observed in this study, assessment of knowledge and attitudes revealed that participants from developed countries are generally more knowledgeable 
and had better attitudes during the pandemic as compared to those from developing countries. This may be explained by the markedly significant difference in the level and standard of education and income between these two types of countries. According to data from 2019, Pakistan had a Gross National Income (GNI) per capita of \$1,410, while the United States had a GNI per capita of $\$ 65,850 .{ }^{25}$ Similarly, according to data from 2011, the percentage of population in the United States holding a college degree was approximately $29.3 \%$ as compared to only $7.4 \%$ in Pakistan. ${ }^{26}$ This is supported by findings from similar studies which found high income earners to be more knowledgeable about COVID-19 and documented income and education to be highly relevant to knowledge. ${ }^{27}$ It was also noted in this study that the smaller families had greater compliance than larger families and extended families. Similarly, participants living in small houses with three rooms or less realized the importance of precautionary measures. There is significant difference between the number of rooms and safe distancing $(\mathrm{p}$ value $=0.031)$ with $36.8 \%$ from small houses, closely followed by a figure of $34.3 \%$ from the average sized houses. This may be because those living in close knit family settings need to be more cautious in order to avoid transmission to other family members.

Anxiety related to the COVID-19 disease is worsened by regulations that call for strict quarantining. Previous studies explain that the mental burden stems from isolation, missing work, not getting paid and personal trauma. ${ }^{28}$ In this study, 179 respondents were in favour of leaving the house for work related activities, 109 believed it was acceptable to go out to meet close friends and family, whereas 203 agreed that one must go out only for necessities such as groceries or medications. Over a hundred participants also admitted that emotional trauma was an important reason for breaking quarantine; these factors included feeling of claustrophobia, cabin fever, domestic violence, and inability to care for family members for extended periods of time (Figure 2). Out of the 130 responses in favour of lifting the lockdown, $21 \%$ stated effect on mental health as a primary reason whereas $85 \%$ of the responses stated effect on economy as the major reason (Figure 2). Despite the negative mental and physical effects of quarantining, 22.5\% of participants found the time off to connect with abandoned hobbies, $23.7 \%$ were able to spend extra time with family members they were quarantining with, and 49\% engaged in online courses and social media activities (Figure 2). Participants were well-aware of the various myths surrounding the pandemic and agreed that the administrations are required to implement these measures out of need; and $66.5 \%$ admitted the need for verifying authenticity of information from credible sources such as 
WHO, CDC or UNICEF to avoid mass hysteria. When asked about their opinion on compliance to COVID-19 protocols once the lockdown is lifted without the availability of vaccines or definitive treatment, $45 \%$ of the participants in the current study were of the view that they would continue with current precautions, and 40\% agreed to exercising increased caution (Figure 2). However, vaccinations have now become a viable means of attaining protection against the disease. Response is largely dependent on adequate population coverage. With increasing vaccine hesitancy, this has been made difficult. Hesitancy stems from having insufficient information about the utility and safety of COVID-19 vaccines. This problem is further exacerbated not only by poor governance, but also by cultural barriers and misbeliefs. ${ }^{29}$ Stringent religious views and superstitious beliefs have led to increased mistrust in vaccinations. ${ }^{30}$ This is particularly true in developing countries with lower literacy rates and socioeconomic status. In developed countries, antivaxxers continue to undermine the effectiveness of vaccination programs. ${ }^{29}$ Johns Hopkins Medicine has countered several false claims and explained that COVID-19 vaccines were developed using mRNA and do not contain foreign objects like magnets or implants. ${ }^{31}$ The American College of Obstetricians and Gynaecologists recommend vaccinations in pregnant females and reason that vaccines have no adverse effects on fertility. ${ }^{32}$

\section{Strengths and limitations}

Survey bias may be present in the study. Data was collected via social media platforms and may not be representative of the entire population. High- and low-income groups were added as generalized ranges and may not be truly representative. Additionally, the number of people in the developed and developing groups in this study are not standardised which can introduce bias.

\section{Conclusion}


Compliance to preventative measures is essential in curbing the spread of highly contagious diseases such as COVID-19. Disparity exists between the developed and developing world due to varying socioeconomic factors and quality of life, which include factors such as education, easy accessibility to information and quality healthcare provision. Although, assessment of knowledge and attitude showed more promising results in the developed subgroup. Increased availability of information and greater incomes ensure greater knowledge amongst these subjects. However, practices were better followed by participants from the developing countries, owing to herd mentality and greater time available for preparation as COVID was introduced to the developing targeted countries much later. Even so despite the access to vast information, compliance to preventative measures was poor in both developing and developed countries. Mass campaigns are necessary to increase precautionary measures. This is especially important with the advent of vaccination programs as the myths surrounding vaccines jeopardize public health efforts. Greater allocation to health and education budgets may be helpful in increasing awareness and targeting misinformation and misbeliefs. Effects on mental health are an important reason for noncompliance and measures such as opening park, and arranging safe cycling and walking tracks, as well as providing online counselling may be especially helpful.

\section{References}

1. Singhal T. A review of coronavirus disease-2019 (COVID-19). Indian J Pediatr 2020;87:281-6.

2. Javed B, Sarwer A, Soto EB, Mashwani Z-R. Is Pakistan's response to coronavirus (SARSCoV-2) Adequate to prevent an outbreak? Front Med 2020;7:158.

3. Worldometer [Internet]. COVID live update: 178,386,378 cases and 3,861,742 deaths from the coronavirus. Accessed 2021 Jun 18. Available from: https://www.worldometers.info/coronavirus/ 
4. Wilder-Smith A, Freedman DO. Isolation, quarantine, social distancing and community containment: pivotal role for old-style public health measures in the novel coronavirus (2019-nCoV) outbreak. J Travel Med 2020;27:taaa020.

5. Centers for Disease Control and Prevention. COVID-19 vaccination. 2020. Accessed 2021 Jun 18. Available from: https://www.cdc.gov/coronavirus/2019-ncov/vaccines/fullyvaccinated.html

6. NCOC.gov.pk NCO [Internet]. National Command Operation Center. Accessed 2021 Jun 18. Available from: https://ncoc.gov.pk/covid-vaccination-en.php

7. United Nations. Country classification 2014. Accessed 2021 Jun 18. Available from: https://www.un.org/en/development/desa/policy/wesp/wesp_current/2014wesp_country_cl assification.pdf

8. Harvard Catalyst [Internet]. REDCap (Research Electronic Data Capture). Accessed 2021 Jun 18. Available from: https://redcap.aws.rits.hms.harvard.edu/

9. Wikipedia [Internet]. COVID-19 pandemic in Pakistan. Accessed 2021 Jun 18. Available from: https://en.wikipedia.org/wiki/COVID-19_pandemic_in_Pakistan

10. World Health Organization. Timeline: WHO's COVID-19 response. Accessed 2021 Jun 18. Available from: https://www.who.int/emergencies/diseases/novel-coronavirus2019/interactive-timeline

11. Thiagarajan K. Why is India having a covid-19 surge? BMJ 2021;373:n1124.

12. Nishtar S, Boerma T, Amjad S, et al. Pakistan's health system: performance and prospects after the 18th Constitutional Amendment. Lancet 2013;381:2193-206.

13. Centers for Disease Control and Prevention. Interim Public Health Recommendations for Fully Vaccinated People. 2020. Accessed 2021 Jun 18. Available from: https://www.cdc.gov/coronavirus/2019-ncov/vaccines/fully-vaccinated-guidance.html

14. AARP [Internet]. Does your state have a mask mandate due to coronavirus? Accessed 2021 Jun 18. Available from: https://www.aarp.org/health/healthy-living/info-2020/states-maskmandates-coronavirus.html

15. Cleveland clinic [Internet]. Already vaccinated? Here's why you shouldn't stop wearing your face mask yet. 2021. Accessed 2021 Jun 18. Available from: https://health.clevelandclinic.org/already-vaccinated-heres-why-you-shouldnt-stopwearing-your-face-mask-yet/

16. World Health Organization. Coronavirus disease (COVID-19): Vaccines. Accessed 2021 Jun 18. Available from: https://www.who.int/news-room/q-a-detail/coronavirus-disease-(covid19)-vaccines

17. World Health Organization. Coronavirus disease (COVID-19): Serology, antibodies and immunity. Accessed 2021 Jun 18. Available from: https://www.who.int/news-room/q-adetail/coronavirus-disease-covid-19-serology

18. Sanyaolu A, Okorie C, Marinkovic A, et al. Comorbidity and its impact on patients with COVID-19. Sn Compr Clin Med 2020. Online ahead of print. 
19. Center SOPS NCO [Internet]. National Command Operation Center. Accessed 2021 Jun 18. Available from: https://ncoc.gov.pk/sop.php

20. Vlassoff C. Gender differences in determinants and consequences of health and illness. J Health Popul Nutr 2007;25:47-61.

21. Zhong B-L, Luo W, Li H-M, et al. Knowledge, attitudes, and practices towards COVID-19 among Chinese residents during the rapid rise period of the COVID-19 outbreak: a quick online cross-sectional survey. Int J Biol Sci 2020;16:1745-52.

22. Miller TA, DiMatteo MR. Importance of family/social support and impact on adherence to diabetic therapy. Diabetes Metab Syndr Obes Targets Ther 2013;6:421-6.

23. UNDP Pakistan [Internet]. Unleashing the potential of a young Pakistan | Human Development Reports. Accessed 2021 Jun 18. Available from: http://hdr.undp.org/en/content/unleashing-potential-young-pakistan

24. The New York Times [Internet]. The New Culture War - 2020. Accessed 2021 Jun 18. Available from: https:/www.nytimes.com/2020/05/07/us/politics/liberal-conservativecoronavirus.html

25. Worldbank [Internet]. GNI per capita, Atlas method (current US\$) Data. Accessed 2021 Jun 18. Available from: https://data.worldbank.org/indicator/NY.GNP.PCAP.CD

26. Worldbank [Internet]. Educational attainment, at least Bachelor's or equivalent, population 25+, total (\%) (cumulative) Data. Accessed 2021 Jun 18. Available from: https://data.worldbank.org/indicator/SE.TER.CUAT.BA.ZS?most_recent_year_desc=false

27. Al-Hanawi MK, Angawi K, Alshareef N, et al. Knowledge, attitude and practice toward COVID-19 among the public in the Kingdom of Saudi Arabia: A cross-sectional study. Front Public Health 2020;8:217.

28. Saurabh K, Ranjan S. Compliance and psychological impact of quarantine in children and adolescents due to Covid-19 pandemic. Indian J Pediatr 2020;87:532-6.

29. Burgess RA, Osborne RH, Yongabi KA, et al. The COVID-19 vaccines rush: participatory community engagement matters more than ever. Lancet 2021;397:8-10.

30. Khan YH, Mallhi TH, Alotaibi NH, et al. Threat of COVID-19 vaccine hesitancy in Pakistan: The need for measures to neutralize misleading narratives. Am J Trop Med Hyg 2020;103:603-4.

31. Johns Hopkins Medicine [Internet]. COVID-19 vaccines: Myth versus fact. Accessed 2021 Jun 18. Available from: https://www.hopkinsmedicine.org/health/conditions-anddiseases/coronavirus/covid-19-vaccines-myth-versus-fact

32. ACOG [Internet]. Medical experts continue to assert that COVID vaccines do not impact fertility. Accessed 2021 Jun 18. Available from: https://www.acog.org/news/newsreleases/2021/02/medical-experts-assert-covid-vaccines-do-not-impact-fertility 
Table 1: Demographics of the population

\begin{tabular}{|c|c|c|}
\hline \multicolumn{3}{|l|}{ Demographics and socioeconomic status } \\
\hline & $\begin{array}{c}\text { Frequency (\%) } \\
n=394\end{array}$ & p value \\
\hline $\begin{array}{l}\text { Gender } \\
\text { Male } \\
\text { Female }\end{array}$ & $\begin{array}{l}232(58.9) \\
162(41.1)\end{array}$ & \multirow[t]{2}{*}{0.054} \\
\hline $\begin{array}{l}\text { Age }(\text { mean } \pm \text { SD) } \\
\text { Male } \\
\text { Female }\end{array}$ & $\begin{array}{l}28.4 \pm 10.1 \\
30.8 \pm 14.9\end{array}$ & \\
\hline $\begin{array}{l}\text { Countries* } \\
\text { Developed } \\
\text { Developing }\end{array}$ & $\begin{array}{l}155(39.3) \\
239(60.7)\end{array}$ & \multirow{3}{*}{$<0.001$} \\
\hline $\begin{array}{l}\text { Income } \\
<\text { Rs. 200,000/USD 4500 } \\
\text { Rs. 200,000-400,000/USD 4500-5500 } \\
>\text { Rs. 400,000/USD 5500 }\end{array}$ & $\begin{array}{c}240(60.9) \\
70(17.8) \\
84(21.3)\end{array}$ & \\
\hline $\begin{array}{l}\text { Education } \\
\text { High school } \\
\text { College degree } \\
\text { Post-graduation }\end{array}$ & $\begin{array}{l}116(29.4) \\
157(39.8) \\
121(30.7)\end{array}$ & \\
\hline Number of rooms in the house (median $\pm I Q R$ ) & $03 \pm 2$ & \multirow[b]{2}{*}{ N/A } \\
\hline Number of family members living in the house (median $\pm Q R)$ & $05 \pm 3$ & \\
\hline \multicolumn{3}{|l|}{ COVID-19 history } \\
\hline $\begin{array}{l}\text { Self-COVID-19 infection } \\
\text { Yes } \\
\text { No }\end{array}$ & $\begin{array}{c}51(12.9) \\
343(87.1)\end{array}$ & 0.854 \\
\hline $\begin{array}{l}\text { Self-comorbidities }^{\#} \\
\text { Present } \\
\text { Absent }\end{array}$ & $\begin{array}{l}162(41.1) \\
232(58.9)\end{array}$ & 0.206 \\
\hline $\begin{array}{l}\text { Family members COVID-19 positivity } \\
\text { Yes } \\
\text { No }\end{array}$ & $\begin{array}{l}120(30.5) \\
274(69.5)\end{array}$ & 0.491 \\
\hline
\end{tabular}




\begin{tabular}{|l|r|l|}
\hline Family members with comorbidities $^{\#}$ & & \\
Yes & $111(28.2)$ & $<0.001$ \\
No & $283(71.8)$ & \\
\hline
\end{tabular}

*Developed countries included are USA, UK, Germany, Ireland, Canada, Australia, and Netherlands. Developing countries included are Pakistan, India, UAE, Turkey, Sudan, Malaysia and Egypt.

(https://www.un.org/en/development/desa/policy/wesp/wesp current/2014wesp country classification.pdf)

\#Comorbidities included were diabetes mellitus, hypertension, immunosuppressive state (cancer, organ transplant), asthma, heart and lung diseases, kidney diseases or ongoing dialysis and liver dysfunction. 
Table 2: Factors associated with compliance rate among population

\begin{tabular}{|c|c|c|c|c|}
\hline & $\begin{array}{l}\text { Compliance to } \\
\text { hand washing } \\
\begin{array}{c}(\%) \\
n=394\end{array}\end{array}$ & $\begin{array}{c}\text { Compliance to } \\
\text { wearing mask } \\
\left(\begin{array}{c}\%) \\
\text { n=394 }\end{array}\right.\end{array}$ & $\begin{array}{c}\text { Compliance to } \\
\text { keeping safe } \\
\text { distance }(\%) \\
\text { n=394 }\end{array}$ & $\begin{array}{c}\text { Compliance to } \\
\text { decreasing } \\
\text { frequency of } \\
\text { going out (\%) } \\
\text { n=394 }\end{array}$ \\
\hline \multicolumn{5}{|c|}{ Demographics } \\
\hline $\begin{array}{l}\text { Gender } \\
\text { Male } \\
\text { Female } \\
\text { p value }\end{array}$ & $\begin{array}{c}183(46.4) \\
120(30.5) \\
0.265\end{array}$ & $\begin{array}{c}200(50.8) \\
141(35.8) \\
0.812\end{array}$ & $\begin{array}{c}185(46.9) \\
119(30.2) \\
0.144\end{array}$ & $\begin{array}{c}187(47.5) \\
130(32.9) \\
0.93\end{array}$ \\
\hline $\begin{array}{l}\text { Age (years) } \\
\text { Youth }(18-24) \\
\text { Adults }(25-64) \\
\text { Seniors }(>64) \\
\text { p value }\end{array}$ & $\begin{array}{c}146(37.1) \\
151(38.3) \\
6(1.52) \\
0.179 \\
\end{array}$ & $\begin{array}{c}163(41.4) \\
169(42.9) \\
9(2.30) \\
0.668\end{array}$ & $\begin{array}{c}135(34.3) \\
162(41.2) \\
7(1.77) \\
\mathbf{0 . 0 0 3} \\
\end{array}$ & $\begin{array}{c}148(37.6) \\
158(40.1) \\
11(2.79) \\
0.126 \\
\end{array}$ \\
\hline $\begin{array}{l}\text { Countries } \\
\text { Developed } \\
\text { Developing } \\
\text { p value }\end{array}$ & $\begin{array}{c}124(31.5) \\
179(45.4) \\
0.240\end{array}$ & $\begin{array}{c}141(35.8) \\
200(50.8) \\
\mathbf{0 . 0 3 8}\end{array}$ & $\begin{array}{c}139(35.3) \\
165(41.9) \\
<\mathbf{0 . 0 0 1}\end{array}$ & $\begin{array}{c}134(34.0) \\
183(46.4) \\
\mathbf{0 . 0 1 6}\end{array}$ \\
\hline $\begin{array}{l}\text { Income } \\
<\text { Rs. } 200,000 / \mathrm{USD} \\
4500 \\
\text { Rs. } 200,000- \\
400,000 / \text { USD } \\
4500-5500 \\
>\text { Rs. } 400,000 / \mathrm{USD} \\
5500 \\
\text { p value }\end{array}$ & $\begin{array}{l}178(45.2) \\
54(13.7) \\
71(18.0)\end{array}$ & $\begin{array}{c}205(52.0) \\
60(15.2) \\
76(19.3) \\
0.493\end{array}$ & $\begin{array}{c}185(46.9) \\
52(13.2) \\
67(17.0) \\
0.723\end{array}$ & $\begin{array}{c}191(48.5) \\
56(14.2) \\
70(17.8) \\
0.753\end{array}$ \\
\hline $\begin{array}{l}\text { Education } \\
\text { High school } \\
\text { College degree } \\
\text { Post-graduation } \\
\text { p value }\end{array}$ & $\begin{array}{c}91(23.1) \\
119(30.2) \\
93(23.6) \\
0.876\end{array}$ & $\begin{array}{c}103(26.1) \\
133(33.8) \\
105(26.7) \\
0.619\end{array}$ & $\begin{array}{c}83(21.1) \\
120(30.5) \\
101(25.6) \\
0.089\end{array}$ & $\begin{array}{c}89(22.6) \\
130(32.9) \\
98(24.9) \\
0.450\end{array}$ \\
\hline \multicolumn{5}{|c|}{ COVID-19 history } \\
\hline $\begin{array}{l}\text { Self-COVID-19 } \\
\text { positivity } \\
\text { Yes } \\
\text { No } \\
\text { p value }\end{array}$ & $\begin{array}{c}44(11.2) \\
259(65.7) \\
0.089\end{array}$ & $\begin{array}{c}47(11.9) \\
294(74.6) \\
0.208\end{array}$ & $\begin{array}{c}42(10.7) \\
262(66.5) \\
0.344\end{array}$ & $\begin{array}{c}35(8.88) \\
282(71.6) \\
\mathbf{0 . 0 2 2}\end{array}$ \\
\hline
\end{tabular}




\begin{tabular}{|l|c|c|c|c|}
\hline Self-comorbidities & & & & \\
present & $126(31.9)$ & $140(35.5)$ & $121(30.7)$ & $123(31.2)$ \\
Nos & $177(44.9)$ & $201(51.0)$ & $183(46.4)$ & $194(49.2)$ \\
p value & 0.731 & 0.950 & 0.330 & 0.058 \\
\hline Family members & & & & \\
contracted & & & & \\
COVID-19 & $93(23.6)$ & $106(26.9)$ & $92(23.4)$ & $95(24.1)$ \\
Yes & $210(53.2)$ & $235(59.6)$ & $212(53.8)$ & $222(56.3)$ \\
No & 0.853 & 0.492 & 0.878 & 0.669 \\
p value & & & & \\
\hline Family members & & & & \\
with & & $99(25.1)$ & $83(21.1)$ & $231(58.6)$ \\
comorbidities & $94(23.9)$ & $242(61.4)$ & $221(56.1)$ & 0.350 \\
Yes & $209(53.0)$ & 0.336 & 0.480 & \\
No & $\mathbf{0 . 0 2 2}$ & & & \\
p value & & & & \\
\hline
\end{tabular}




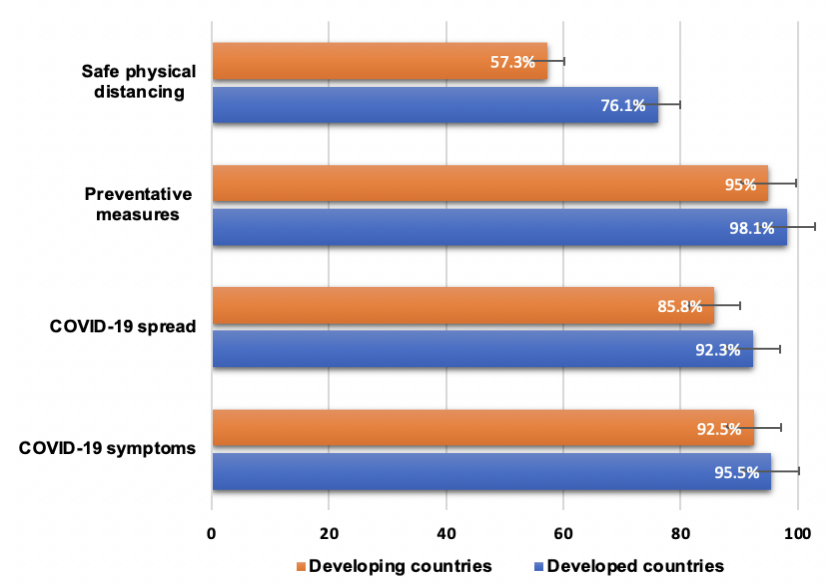

A: Knowledge about the COVID-19 disease

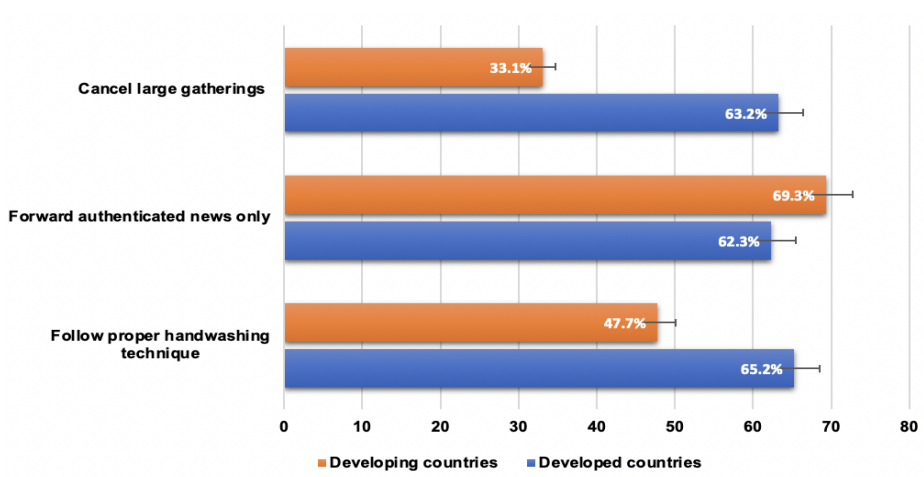

B: Attitude towards COVID-19 pandemic

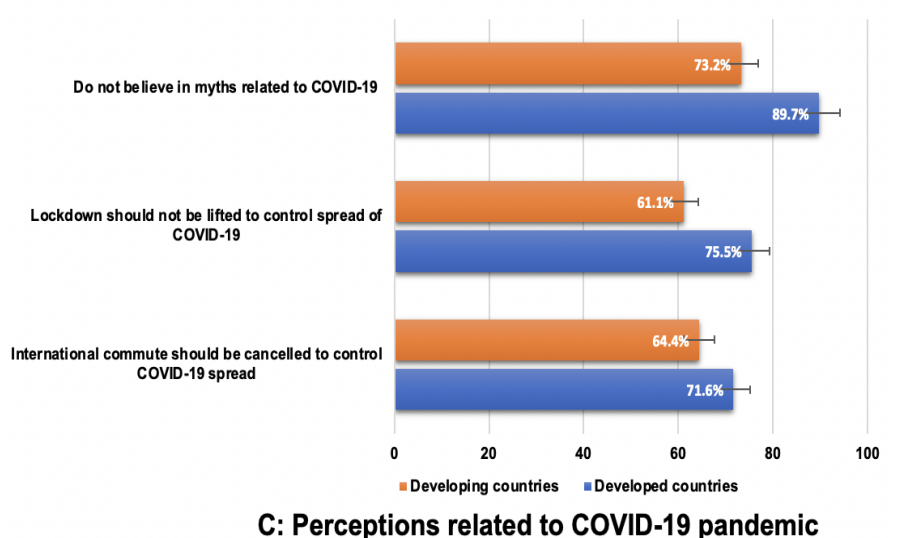

Figure 1: Comparison of knowledge, attitude, and practices during COVID-19 between developed and developing countries population. 


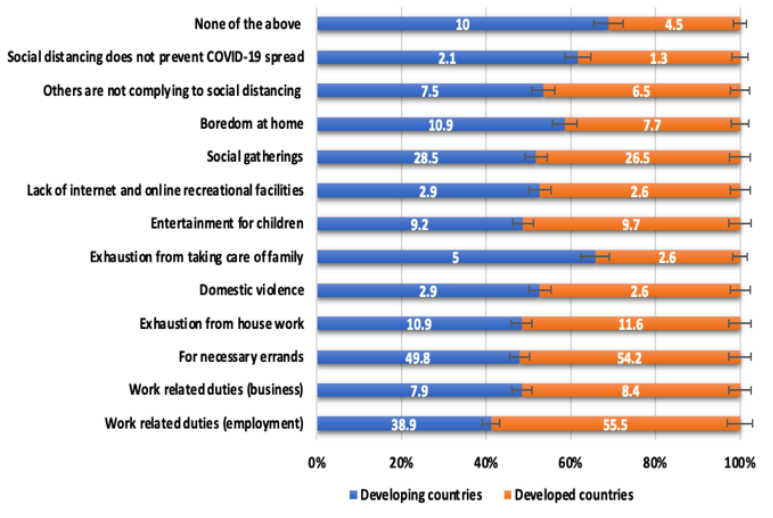

A: Reasons for leaving house during pandemic

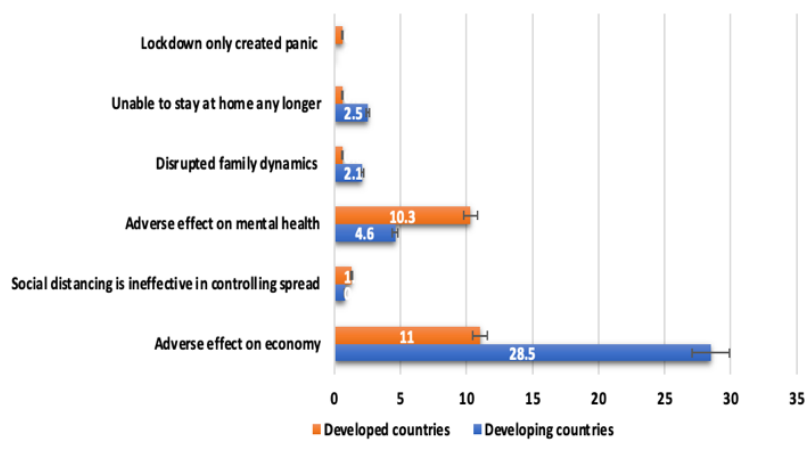

C: Reasons for favoring the lifting of lockdown

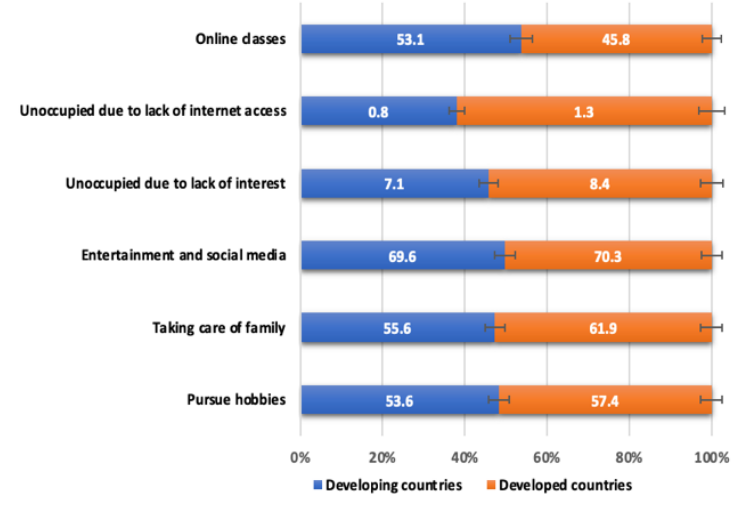

B: Ways of spending time during lockdown

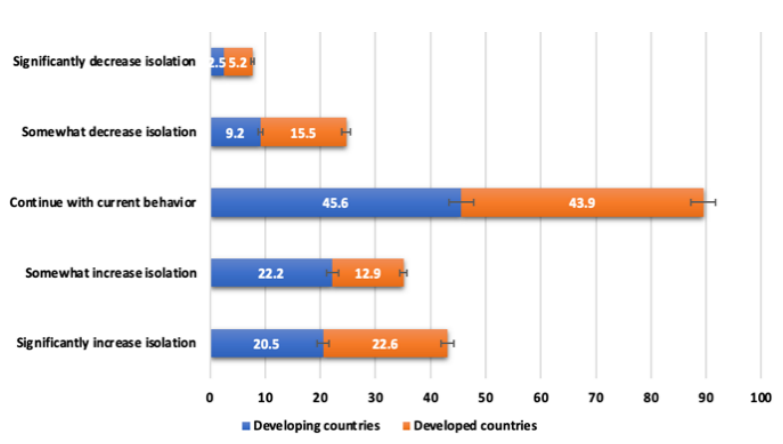

D: Changes in social distancing behavior once lockdown is lifted

Figure 2: Comparison of attitude and perceptions towards the lockdown of the developing and developed countries population. 